\title{
Clinical Evaluation of the Safety and Effectiveness of Heptonica: A Ghanaian Hepatorestorative Polyherbal Product
}

\author{
A. O. Agyemang $\mathbb{D}^{1,2}$ M. L. K. Mensah ${ }^{1},{ }^{3}$ R. C. Yamile, ${ }^{4}$ A. Ocloo ${ }^{1},{ }^{5,6}$ A. A. Appiah, ${ }^{5}$ \\ A. Y. Mensah $\mathbb{D}^{7}{ }^{7}$ and K. P. Thomford ${ }^{3}$ \\ ${ }^{1}$ Department of Herbal Medicine, Upper West Regional Hospital, Ghana Health Service, Wa, Ghana \\ ${ }^{2}$ Institute of Traditional and Alternative Medicine, University of Health and Allied Sciences, Ho, Ghana \\ ${ }^{3}$ Department of Herbal Medicine, Faculty of Pharmacy of Pharmaceutical Sciences, College of Health Sciences, \\ Kwame Nkrumah of University and Technology, Kumasi, Ghana \\ ${ }^{4}$ Department of Medicine, Upper West Regional Hospital, Ghana Health Service, Wa, Ghana \\ ${ }^{5}$ Centre for Plant Medicine Research, Mampong-Akuapem, Ghana \\ ${ }^{6}$ Department of Biochemistry, Cell and Molecular Biology, University of Ghana, Legon, Ghana \\ ${ }^{7}$ Department of Pharmacognosy, Faculty of Pharmacy of Pharmaceutical Sciences, College of Health Sciences, \\ Kwame Nkrumah of University and Technology, Kumasi, Ghana \\ Correspondence should be addressed to A. O. Agyemang; aoagyemang@uhas.edu.gh
}

Received 17 March 2020; Accepted 3 June 2020; Published 22 June 2020

Academic Editor: Evan P. Cherniack

Copyright (c) 2020 A. O. Agyemang et al. This is an open access article distributed under the Creative Commons Attribution License, which permits unrestricted use, distribution, and reproduction in any medium, provided the original work is properly cited.

\begin{abstract}
The incidence of liver diseases is increasing globally, and many patients in developing countries are resorting to the use of herbal products as treatment. This study was aimed at establishing the safety and effectiveness outcomes for patients with deranged liver panel treated with a Ghanaian finished polyherbal product. The product Heptonica is prepared by CPMR from three medicinal plants: Bidens pilosa, Citrus aurantifolia, and Trema orientalis. Fifty (50) participants with clinical and biochemical signs of liver impairment were purposively recruited and treated for a period of 28 days. Participants received Heptonica at a dose of $30 \mathrm{~mL} 8$ hourly after meals for the treatment period. Clinical and biochemical evaluation (liver panel test, renal function test, haematology, and urinalysis) of subjects for the safety and effectiveness of the product was undertaken at days 0 (baseline), 14, and 28. Compared to the baseline values, Heptonica did not have any untoward effect on renal function, haematological parameters, and urine parameters of subjects. Clinical and liver panel results of the participants also improved compared to the baseline: serum aspartate transaminase (AST) $(p<0.0001)$, alanine transaminase (ALT) $(p<0.0001)$, gamma-glutamyltransferase (GGT) $(p-0.0013)$, total bilirubin $(p-0.0136)$, direct bilirubin $(p<0.0001)$, total proteins $(p-0.0409)$, and alkaline phosphates $(p-0.0284)$. Level of albumin showed no significant difference within the study period. The outcome of this study indicates Heptonica has hepatorestorative action with no observable toxicity and can be used with confidence as indicated as a liver tonic.
\end{abstract}

\section{Introduction}

The liver is an organ responsible for many important physiological functions including metabolic, circulatory, immunological, storage, and endocrine activities in the human body. Liver (hepatic) diseases comprise a wide range of complex conditions that affect the structure and functions of the liver. Currently, about 844 million people are living with different forms of liver diseases leading to over 2 million deaths annually.
Mortality from liver diseases is expected to rise across the world [1-3]. Lack of affordable and accessible therapeutic agents for the treatment of liver diseases is impeding the quality of life of patients as well as increasing mortality [4]. Ghana reported 7,833 mortalities due to liver diseases in the year 2017 that translated to $3.72 \%$ of the total annual mortality [5].

Liver diseases are mainly managed on a supportive basis, which includes the removal of causative agents and treating the underlying causes [6]. The choice of therapy depends on 
many factors including the type of liver disease, the stage and intensity, health status of the individual, and the availability of professionals and healthcare facilities for specific intervention services [7]. Despite the high advances in modern science, it is still a challenge to get safe and efficacious agents to improve hepatic protection and enhance hepatic functions [8].

Globally, there are limited therapeutic agents for preventing and managing liver diseases. The few therapeutic options are very expensive and not accessible to many people especially those in developing countries $[9,10]$. There is a great need to search for more agents that can protect the liver and manage and treat liver diseases. Some of the few allopathic drugs for treating liver diseases are also limited in efficacy and compounded by toxic side effects [11].

Herbal products are used traditionally in the prevention, treatment of many diseases, and for improving the general wellbeing of humans including as a remedy for liver diseases and to restore normal functions of the liver [9]. However, most herbal products have not been subjected to standardization or clinical studies to prove their safety and effectiveness in humans [12]. Although there are claims of many years of using herbal medicines for liver diseases, many of such claims do not provide evidence concerning their safety and effectiveness in human clinical studies [13]. In Ghana, affordable and readily available herbal medicines are a means of treatment of liver diseases. One of such products is Heptonica which has been used for over 30 years at the Centre for Plant Medicine Research (CPMR) and the past seven years by medical herbalists at some of the 35 public hospitals which are pilot centres for the integration of herbal medicine into the public healthcare system in Ghana. The three plant components of Heptonica (Citrus aurantifolia (Rutaceae), Bidens pilosa (Compositae), and Trema orientalis Linn. Blume (Ulmaceae)) have ethnobotanical evidence of use in the management of liver diseases [14]. However, there has not been a comprehensive clinical study of the finished herbal product to establish its potential in therapy. The aim of this study was to provide scientific data on the safety and effectiveness of Heptonica for the treatment and/or management of liver diseases in humans with deranged liver panel.

\section{Materials and Methods}

2.1. Materials. Heptonica is a liquid finished herbal product produced and supplied by the Centre for Plant Medicine Research (CPMR) located at Mampong-Akuapem in the Eastern Region of Ghana. Heptonica is produced from the dried parts of the following: leaves of Citrus aurantifolia (Rutaceae), the aerial part of Bidens pilosa (Compositae), and the stem bark of Trema orientalis Linn. Blume (Ulmaceae). It is packaged in $330 \mathrm{~mL}$ plastic amber bottles for oral administration for adults only, at the dose of $30 \mathrm{~mL}$, three times daily after meals.

\subsection{Methods}

2.2.1. Study Design. An open-label prospective noncomparative clinical study was conducted among clients that patronize the Herbal Medicine Services at the Upper West Regional Hospital (UWRH). Convenience sampling technique was used to select 50 clients for the study based on the inclusion and exclusion criteria [15]. Clients with suspected liver diseases were tested for liver panel, renal function (RFT), full blood count (FBC), and urinalysis. Clients with deranged (below or above reference range) liver panel results were enrolled in the study at the Upper West Regional Hospital (UWRH). There were no positive and negative controls for the study $[16,17]$. Haematological tests were done using Mindray 3000 Haematology analyzer while Mindray 3000 Biochemistry analyzer was used to run the liver and renal biochemistry tests. All tests were done according to the manufacturer's instructions. Structured questionnaires were used to obtain data such as age, sex, education level, marital status, contact number, symptoms, signs as well as a Karnofsky scale assessment for quality of life.

2.2.2. Inclusion and Exclusion Criteria. The inclusion criteria for enrolment into this study comprised clients with deranged liver disease, confirmed by a biochemistry laboratory test, adults aged between 18 and 65 years, outpatients (both males and females), clinically stable subjects with no life-threatening conditions, ability to report for follow-up, and the willingness to sign consent forms.

Subjects were excluded from the study when they were below 18 years of age, critically ill clients, clients on admission, clients with a high temperature above $39^{\circ} \mathrm{C}$, evidence of severe liver disease, people with comorbidities, and clients on other hepatoprotectives, recreational, or other drugs 14 days before the study. Pregnant women, breastfeeding mothers, people who are unable to come for followups, and clients with any condition that might compromise any of the biochemical parameters were also excluded.

2.2.3. Treatment and Follow-Ups. As mentioned above, fifty (50) participants, who met the inclusion criteria were selected for the study. Vital signs were checked, clinical assessment and laboratory tests (liver panel test, renal function test (RFT), full blood count (FBC), and urinalysis) were performed on day zero (0) for baseline data, and each subject was given two weeks supply of the herbal preparation and was asked to report for follow-ups on days 14 and 28 at the hospital.

During each follow-up, checking of vitals, clinical assessment, and laboratory tests were repeated. Home visits and phone calls were used to monitor compliance and possible adverse effects and to remind subjects of their next hospital visits. A participant was withdrawn if he/she clinically deteriorated or worsened during the study period. Any individual who developed adverse drug reaction to Heptonica was also withdrawn from the research. Clients were also given the opportunity to voluntarily withdraw from the study if they so wished with or without explanation to the researchers.

2.2.4. Assessment of Safety. The data from clinical assessment, renal function test, haematological assessment (FBC), urinalysis, abdominal ultrasound, and adverse effects questionnaires were used to assess the safety profile of Heptonica in humans within the 28 days of drug administration. 
2.2.5. Assessment of Effectiveness. Liver panel biochemistry is an established method of assessing liver activity and it is used as a tool in assessing the integrity of the liver. The ability to significantly normalize or reverse deranged liver parameters was the primary endpoint of effectiveness with an improvement of quality of life as the secondary endpoint.

2.3. Ethical Considerations. Ethical approval for the study was obtained from the Institutional Review Board (Committee on Human Research, Publication and EthicsCHRPE) at the School of Medical Sciences (SMS), Kwame Nkrumah University of Science and Technology (KNUST) and Komfo Anokye Teaching Hospital (KATH) with reference number: CHRPE/AP/038/18. Approval was also obtained from the Upper West Regional Health Directorate and the Upper West Regional Hospital, the site for the study. All participants agreed and signed informed consent forms and were assigned codes to protect their identities.

2.4. Statistical Analysis. GraphPad Prism version 8.02 for Windows (GraphPad Software, San Diego, CA, USA) and SPSS version 20.0 for Windows (IBM, Chicago, IL, USA) were used for all the data analysis. $p \leq 0.05$ was considered statistically significant in all analysis.

\section{Results and Discussion}

3.1. Demographics and Aetiology of Participants Liver Diseases. Out of the 50 participants, 39 (78\%) were males and the remaining 11 (22\%) were females (Table 1$)$. This observation is consistent with findings from other studies confirming gender differences in the prevalence of liver diseases [18]. The high rate of the deranged liver panel in males may be attributed to their risky lifestyle. Multiple sexual partners and abuse of alcohol and other drugs are more common in males than in females [19]. The data also showed that more youth and more married people had deranged liver panel compared to the other groups. Majority of the subjects were in the 20-29-year group (32\%) followed by the $30-39$-year group $(28 \%)$ with the least being those in the 50-59-year group (6\%).

Viral hepatitis (hepatitis B and C) was found to be the major cause of deranged liver panel among the participants accounting for $66 \%$ of the cases. The cause of deranged liver panel could not be ascertained for $22 \%$ (11/50) of the participants and alcoholism and hepatocellular carcinoma (HCC) were responsible for $8 \%(4 / 50)$ and $4 \%(2 / 50)$, respectively, of the cases (Table 1). Viral hepatitis has been associated with deranged liver panel in human studies, thus accounting for the majority of participants [20].

\subsection{Safety of Heptonica in Human Subjects}

3.2.1. Effects of Heptonica on Vital Signs, Renal Function, and Urinalysis of the Subjects. The results of axillary temperature, body weight, and blood pressure of participants at the baseline (day 0) and end of the study (day 28) were as presented in Table 2. All the parameters at the baseline were within the recommended reference range for adults, and although $8 \%$ of the participants complained about fever, the axillary temperatures were within the normal range.

The administration of Heptonica had no significant effect on the axillary temperature, body weight, and blood pressure of the participants over the 28-day period of the study compared to the baseline values except for the slight reduction in the diastolic blood pressure $(p$ value $=0.0496)$. The slight reduction in the diastolic blood pressure was within the recommended adult diastolic blood pressure reference range and therefore not a health risk (Table 2).

The biochemical parameters that were assessed in the participants as a measure of renal function were urea, creatinine, blood urea nitrogen (BUN), and electrolytes (sodium, potassium, and chloride) as shown in Table 2. The presence of one or more deranged biochemistry levels indicates renal injury [21]. The results show that all the parameters were within the reference range on day 0 (baseline) and that administration of the Heptonica did not result in significant changes in any of the parameters except for chloride, where the values on day 28 were significantly higher compared to the baseline (day 0). However, the chloride levels on day 28 were still within the reference range for adults and thus may not pose any health risk.

It has been established in animal studies that Bidens pilosa improves the structure and function of the renal system by enhancing the regeneration of the renal tubules and protects renal tissues exposed to carcinogens [22]. Citrus aurantifolia have been proven to be nephroprotective in animal studies by preventing stress-related renal damage $[23,24]$. The use of the aerial parts of Trema orientalis in animal studies did not provide any evidence of renal injury in animal toxicity studies and so it is expected not to cause renal damage in humans [25].

Furthermore, assessment of urinalysis in the participants revealed a slight rise in urine $\mathrm{pH}(p$ value $=0.049)($ Table 2$)$. Human studies have confirmed that the use of Citrus orientalis results in the alkalinisation of urine by increasing urine $\mathrm{pH}$ [26]. Average pus cell concentrations reduced slightly from $2.84(0.53)$ to $1.86(0.18)(p$ value $=0.050)$ (Table 2). B. pilosa, C. aurantifolia, and T. orientalis have antibacterial properties giving Heptonica ability to reduce pus cells [27-29].

3.2.2. Effects of Heptonica on Quality of Urine. The results of urine quality assessment on days 0 and 28 are shown in Table 3. The Heptonica was able to improve the urine appearance from hazy to clear. All 2 (4\%) of the participants who had blood in urine and positive urine bilirubin got cleared by the $28^{\text {th }}$ day. Bidens pilosa has proven diuretic and choleretic (improving bile flow) properties [30]. Once a product can improve the normal functioning of the liver, it can now conjugate bilirubin and transport it actively into bile as a choleretic and for excretion, thereby reducing plasma bilirubin concentration [31]. Calcium oxalate crystals in the urine as well as the $2 \%$ of urine leucocytes were all reduced within the 28-day period. This result agrees with those from other human studies where oral administration of Citrus 
TABLe 1: Demographics and aetiology of liver diseases of participants.

\begin{tabular}{|c|c|c|c|c|c|c|c|}
\hline \multirow{2}{*}{ Parameters } & \multicolumn{6}{|c|}{ Age (years) } & \multirow{2}{*}{ Total } \\
\hline & $<19$ & $20-29$ & $30-39$ & $40-49$ & $50-59$ & $>60$ & \\
\hline \multicolumn{8}{|l|}{ Gender } \\
\hline Male & 4 & 11 & 14 & 3 & 2 & 5 & $39(78 \%)$ \\
\hline Female & 0 & 5 & 0 & 3 & 1 & 2 & $11(22 \%)$ \\
\hline \multicolumn{8}{|l|}{ Marital status } \\
\hline Single & 4 & 11 & 3 & 1 & 1 & 0 & $20(40 \%)$ \\
\hline Married & 0 & 5 & 11 & 4 & 1 & 6 & $27(54 \%)$ \\
\hline Widow & 0 & 0 & 0 & 1 & 1 & 1 & $3(6 \%)$ \\
\hline \multicolumn{8}{|l|}{ Condition } \\
\hline Hepatitis B & 3 & 14 & 8 & 1 & 0 & 3 & $29(58 \%)$ \\
\hline Hepatitis C & 0 & 0 & 2 & 0 & 2 & 0 & $4(8 \%)$ \\
\hline Alcoholic liver disease & 0 & 0 & 1 & 1 & 0 & 2 & $4(8 \%)$ \\
\hline Unknown cause & 1 & 2 & 2 & 3 & 1 & 2 & $11(22 \%)$ \\
\hline Liver cancer & 0 & 0 & 1 & 1 & 0 & 0 & $2(4 \%)$ \\
\hline
\end{tabular}

TABLE 2: Safety profile of Heptonica on vital signs, renal function, and quantitative urine parameters.

\begin{tabular}{lccc}
\hline Parameter & Day 0 & Day 28 & $p$ value \\
\hline Vital signs $(n, 50)$ & & \\
Temperature $^{\dagger}\left({ }^{\circ} \mathrm{C}\right)$ & $36.10 \pm 0.65$ & $36.00 \pm 0.5$ & 0.438 \\
Weight $(\mathrm{kg})$ & $60.50(12.25)$ & $61.00 \pm 11.25$ & 0.679 \\
Systolic $\mathrm{BP}^{\dagger}(\mathrm{mmHg})$ & $110.0 \pm 25.50$ & $110.0 \pm 20.00$ & 0.149 \\
Diastolic BP $(\mathrm{mmHg})$ & $70.00(10.00)$ & $70.00 \pm 0.00$ & 0.050 \\
Renal function $(n, 50)$ & & & \\
Sodium ${ }^{\dagger}(\mathrm{mmol} / \mathrm{l})$ & $137.7 \pm 6.3$ & $136.6 \pm 8.3$ & 0.248 \\
Potassium $(\mathrm{mmol} / \mathrm{l})$ & $3.9(0.4)$ & $4.1 \pm 0.6$ & 0.478 \\
Chloride $(\mu \mathrm{mol} / \mathrm{l})$ & $104.0(3.2)$ & $106.1 \pm 3.9$ & $\mathbf{0 . 0 0 1}$ \\
Urea $(\mathrm{mmol} / \mathrm{l})$ & $5.4(1.8)$ & $5.45 \pm 2.1$ & 0.829 \\
Creatinine $(\mu \mathrm{mol} / \mathrm{l})$ & $79.4(18.5)$ & $81.5 \pm 21.0$ & 0.613 \\
BUN $(\mathrm{mg} / \mathrm{dl})$ & $15.7(6.4)$ & $15.2 \pm 4.3$ & 0.607 \\
Urine $(n, 50)$ & & & \\
pH & $6.48 \pm 0.13$ & $6.82 \pm 0.14$ & $\mathbf{0 . 0 4 9}$ \\
Specific gravity & $1.02 \pm<0.001$ & $1.02 \pm<0.001$ & 0.414 \\
Pus cell & $2.84(0.53)$ & $1.86 \pm 0.18$ & 0.050 \\
RBC & $0.12(0.08)$ & $0.1 \pm 0.08$ & 0.688 \\
Epithelial cells & $2.76(0.28)$ & $2.74 \pm 0.24$ & 0.363 \\
\hline
\end{tabular}

Data are presented as median (interquartile range (IQR)) (Wilcoxon matched-pairs signed-rank test); " $\dagger$ " indicates that data were parametric and were compared using paired $t$-test. $p \leq 0.05$ was considered significant when compared to baseline.

aurantifolia resulted in the decrease of urine calcium ratio in people with idiopathic calcium renal calculi [26].

\subsubsection{Effect of Heptonica on Haematological Parameters.} The haematological test results (Table 4) showed that all the parameters were within the normal reference range for an African adult on day 0 (baseline) [32]. Administration of Heptonica led to significant increases in haemoglobin level, $\mathrm{MCV}, \mathrm{MCH}$, and MCHC levels at day 28 compared to the baseline values (Table 4). The decoction of the bark of Trema orientalis, one of the components of Heptonica, is used in treating anaemia as a haematinic and this may account for its ability to improve haemoglobin [33]. Trema orientalis has been proven in animal studies as haematoprotective and a
TABle 3: Effect of Heptonica on qualitative urine parameters $(n, 50)$.

\begin{tabular}{|c|c|c|c|c|}
\hline Parameter & Details & $\begin{array}{c}\text { Day } 0 \\
\%\end{array}$ & $\begin{array}{c}\text { Day } 14 \\
\%\end{array}$ & $\begin{array}{c}\text { Day } 28 \\
\%\end{array}$ \\
\hline \multirow{3}{*}{ Urine colour } & Straw & 98 & 84 & 90 \\
\hline & Amber & 2 & 16 & 10 \\
\hline & Clear & 68 & 68 & 78 \\
\hline \multirow[t]{3}{*}{ Urine appearance } & Hazy & 26 & 18 & 16 \\
\hline & Cloudy & 6 & 14 & 6 \\
\hline & Negative & 88 & 84 & 90 \\
\hline \multirow[t]{2}{*}{ Urine proteins } & Trace & 8 & 14 & 6 \\
\hline & Positive & 4 & 2 & 4 \\
\hline Urine glucose & Negative & 100 & 100 & 100 \\
\hline \multirow{2}{*}{ Urine ketones } & Negative & 100 & 100 & 100 \\
\hline & Negative & 96 & 98 & 100 \\
\hline \multirow{2}{*}{ Urine blood } & Trace & 2 & 2 & 0 \\
\hline & Positive & 2 & 0 & 0 \\
\hline \multirow{3}{*}{ Urine bilirubin } & Negative & 96 & 100 & 100 \\
\hline & Positive & 4 & 0 & 0 \\
\hline & Negative & 78 & 84 & 96 \\
\hline \multirow[t]{2}{*}{ Leucocytes } & Trace & 10 & 8 & 4 \\
\hline & Positive & 12 & 8 & 0 \\
\hline \multirow{2}{*}{ Urobilinogen } & Normal & 92 & 98 & 98 \\
\hline & Increased & 8 & 2 & 2 \\
\hline \multirow{2}{*}{ Cast } & Not seen & 100 & 100 & 96 \\
\hline & Seen & 0 & 0 & 4 \\
\hline \multirow{2}{*}{ Crystals } & Not seen & 96 & 98 & 98 \\
\hline & Calcium oxalate & 4 & 2 & 2 \\
\hline
\end{tabular}

haematopoietic agent that improves haemoglobin, $\mathrm{MCH}$, and MCV [34].

3.3. Reported Adverse Effects of Heptonica. Out of the 50 participants who were enrolled in this study, two (2) males (4\%) reported side effects after taking Heptonica. The first client experienced mild diarrhoea for the first two days, but this was resolved when treatment continued without the administration of any other agent. The second client reported itching and macular rashes on the left elbow which stopped after 24 hours on continuing taking the Heptonica. 
Table 4: Assessment of Heptonica on haematological parameters.

\begin{tabular}{lccc}
\hline Haematology & Day 0 & Day 28 & $p$ value \\
\hline WBC & $5.2(0.2)$ & $5.1(0.2)$ & 0.191 \\
Lymph \# & $2.1 \pm 0.1$ & $2.1 \pm 0.1$ & 0.531 \\
Mid \# & $0.5(0.0)$ & $0.45(0.0)$ & 0.156 \\
Gran \# & $2.8(0.2)$ & $2.8(0.2)$ & 0.990 \\
Lymph \% & $39.6(1.5)$ & $41.3(1.5)$ & 0.274 \\
Mid \% & $9.6(0.3)$ & $8.8(0.3)$ & 0.080 \\
Gran \% $^{\dagger}$ & $49.4 \pm 1.3$ & $50.3 \pm 1.5$ & 0.547 \\
Hb $^{\dagger}$ & $13.3 \pm 0.3$ & $13.7 \pm 0.3$ & $\mathbf{0 . 0 0 2}$ \\
RBC $^{\dagger}$ & $4.7 \pm 0.1$ & $4.6 \pm 0.1$ & 0.569 \\
MCV $_{\text {MCH }}$ & $85.9(1.2)$ & $87.6(0.9)$ & $\mathbf{0 . 0 2 9}$ \\
MCHC & $29.4(0.6)$ & $30.8(0.4)$ & $<\mathbf{0 . 0 0 0 1}$ \\
PLT $^{\dagger}$ & $33.4(0.3)$ & $34.0(0.4)$ & $\mathbf{0 . 0 0 2}$ \\
\hline
\end{tabular}

Data are presented as median (interquartile range (IQR)) (Wilcoxon matched-pairs signed-rank test); “ $\dagger$ " indicates that data were parametric and were compared using paired $t$-test. $p \leq 0.05$ was considered significant when compared to baseline. WBC: white blood cells; lymph: lymphocytes; mid cells: monocytes; granulocytes: basophils, eosinophils, and neutrophils; RBC: red blood cells; Hb: haemoglobin; MCV: mean corpuscular volume; $\mathrm{MCH}$ : mean corpuscular haemoglobin; MCHC: mean corpuscular haemoglobin concentration; PLT: platelet.

\subsection{Effectiveness of Heptonica in Human Subjects}

3.4.1. Effect of Heptonica on Reported Clinical Symptoms. Participants reported different symptoms presumably associated with their liver diseases. Symptomatic evaluations of participants were done on days 0 and 28. The recorded symptoms were based on the compilation and frequency of all the complaints of the 50 participants.

As shown in Figure 1, the participants enrolled in the study had ten common presenting complaints among which fatigue and abdominal pains were the most common complaints while abdominal distension was the least. Abdominal ultrasound confirmed the abdominal distension cases as ascites secondary to liver disease. On day 0 , fatigue, abdominal pain, and jaundice were the highest numbers of symptoms complained about in descending order and abdominal distension was the least complaint. On $14^{\text {th }}$ day review, almost all the symptoms complained by the participants showed some level of improvement (data not shown), and further improvement was observed on day 28 (Table 5). Thus, after 28 days of taking Heptonica, most clients experienced maximum relief of symptoms compared with their presenting complaints on day 0 . Jaundice and fever conditions showed the highest recovery of $75 \%$ each while ascites had the lowest change of $100 \%$ mild improvement. These observations imply that the Heptonica appears to be improving the quality of life of the participants.

Heptonica had relieved most of the clients' symptoms especially fever and jaundice but showed less effect on ascites. Total proteins improved significantly but not albumin, implying that the increase came from other proteins other than albumin. The relief of symptoms of participants follows the pattern of improvement seen from the laboratory results and could be suggestive of possible modes of action of Heptonica. By clearing jaundice, Heptonica may be acting as a choleretic reducing hyperbilirubinemia responsible for the

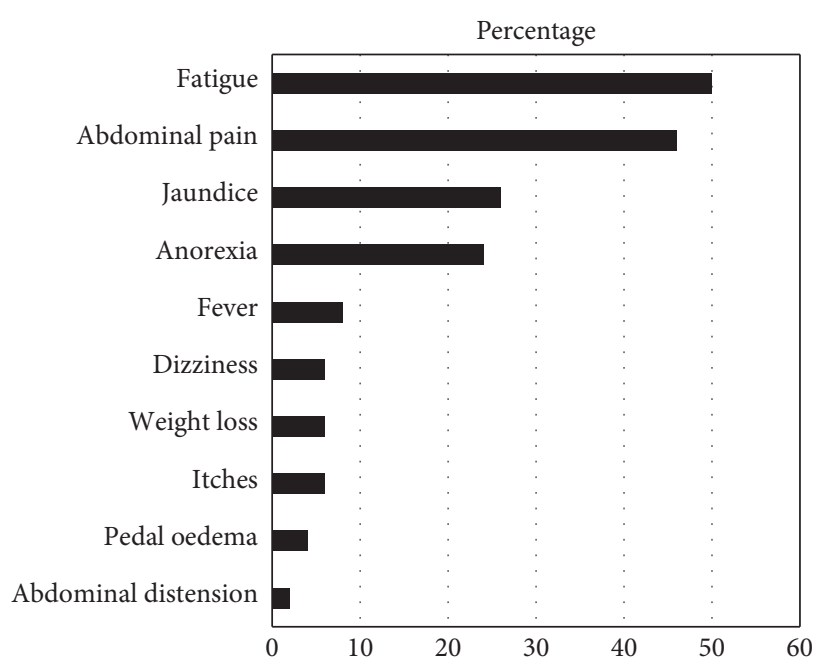

FIgURE 1: Symptoms of liver disease as stated by participants on day 0 .

eyes yellow coloration and pruritus. Heptonica also possess antipyretic activity because it relieved the participants of fever. Bidens pilosa and Citrus aurantifolia have been proven to be antipyretics [35].

\subsubsection{Effect of Heptonica on Liver Panel of Participants.} All participants were assessed for AST, ALT, GGT, bilirubin (total and direct), proteins (total and albumin), and alkaline phosphatase (ALP) on days 0,14 , and 28. Table 6 shows the levels of these parameters on days 0 and 28. Each client enrolled in the study had some form of deranged liver panel on day 0 (baseline). $R$-value which is a ratio of alanine transaminase to alkaline phosphatase (ALT/ALP) is used as an indicator to predict the possible types of liver injuries. At baseline, it was observed that the majority $(90 \%)$ of the participants had a cholestatic liver disease while the remaining $10 \%$ had a cholestatic-hepatocellular disease. There was a significant improvement in the AST, ALT, GGT, bilirubin (total and direct), and ALP after 28 days of treatment compared to the baseline results, suggesting that the herbal preparation (Heptonica) improves liver biochemistry and may be effective in the management of liver diseases. The clearance of jaundice in the eyes of all the $26 \%$ of the participants who were icteric after two weeks of treatment. These patients had jaundice secondary to hepatic causes, and its clearance gives credence to the activity of the intervention product, Heptonica, in the management of liver diseases.

Therapeutic agents are administered in liver diseases to halt the progression of the disease, stimulate and improve hepatocyte integrity and regeneration capacity and liver function, reduce complications as well as treating the underlying cause of the disease, and improve the quality of life of the patient [36]. Heptonica acted as an anti-inflammatory agent by significantly reducing the AST and ALT which are produced in response to liver inflammation (Table 6). Bidens pilosa, Citrus aurantifolia, and Trema orientalis as components of Heptonica have been proven individually to possess 
TABLE 5: Assessed symptoms of liver disease on day 28.

\begin{tabular}{lcccc}
\hline Symptoms & No improvement (\%) & Mild improvement (\%) & Moderate improvement (\%) & Maximum improvement (\%) \\
\hline Jaundice & 0.00 & 0.00 & 25.00 & 75.00 \\
Abdominal pain & 0.00 & 20.83 & 33.33 & 45.83 \\
Fatigue & 0.00 & 5.26 & 36.84 & 57.89 \\
Anorexia & 0.00 & 0.00 & 40.00 & 60.00 \\
Abdominal distension & 0.00 & 100.00 & 0.00 & 0.00 \\
Pedal oedema & 0.00 & 0.00 & 100.00 & 0.00 \\
Itches & 0.00 & 0.00 & 33.33 & 66.67 \\
Weight loss & 0.00 & 50.00 & 0.00 & 50.00 \\
Fever & 0.00 & 0.00 & 25.00 & 75.00 \\
Dizziness & 0.00 & 0.00 & 50.00 & 50.00 \\
\hline
\end{tabular}

TABle 6: Heptonica on types of liver diseases.

\begin{tabular}{|c|c|c|c|}
\hline Liver parameters & Day 0 & Day 28 & $p$ value \\
\hline \multicolumn{4}{|l|}{ General participants $(n, 50)$} \\
\hline AST $(\mathrm{U} / \mathrm{l})$ & $40.5(46.5)$ & $27.8(19.4)$ & $<0.0001$ \\
\hline ALT (U/l) & $44.0(45.6)$ & $25.8(65)$ & $<0.0001$ \\
\hline GGT (U/l) & $58.6(119.5)$ & $40.1(101.6)$ & 0.0013 \\
\hline Total bilirubin $(\mu \mathrm{mol} / \mathrm{l})$ & $25.9(38.2)$ & $15.2(17.6)$ & 0.0136 \\
\hline Direct bilirubin $(\mu \mathrm{mol} / \mathrm{l})$ & $7.6(13.5)$ & $3.8(2.9)$ & $<0.0001$ \\
\hline Total proteins $^{\dagger}(\mathrm{g} / \mathrm{dl})$ & $70.8 \pm 10.5$ & $74.8 \pm 9.3$ & 0.0409 \\
\hline Albumin $^{\dagger}(\mathrm{g} / \mathrm{dl})$ & $42.0 \pm 7.3$ & $42.0 \pm 6.0$ & 0.3432 \\
\hline $\operatorname{ALP}(\mathrm{U} / \mathrm{l})$ & $176.9(175.6)$ & $171.4(153.5)$ & 0.0284 \\
\hline \multicolumn{4}{|l|}{ Cholestatic $(n, 45)$} \\
\hline AST (U/l) & $41.00(47.15)$ & $28.00(19.25)$ & 0.0004 \\
\hline $\operatorname{ALT}(\mathrm{U} / \mathrm{l})$ & $43.00(47.10)$ & $25.00(27.90)$ & 0.0004 \\
\hline GGT (U/l) & $47.30(106.30)$ & $37.00(51.05)$ & 0.0084 \\
\hline Total bilirubin $(\mu \mathrm{mol} / \mathrm{l})$ & $27.80(48.30)$ & $16.40(19.90)$ & 0.0101 \\
\hline Direct bilirubin $(\mu \mathrm{mol} / \mathrm{l})$ & $8.00(12.70)$ & $3.70(3.00)$ & $<0.0001$ \\
\hline Total proteins ${ }^{\dagger}(\mathrm{g} / \mathrm{dl})$ & $70.80 \pm 12.00$ & $75.00 \pm 9.50$ & 0.0928 \\
\hline Albumin $^{\dagger}(\mathrm{g} / \mathrm{dl})$ & $42.00 \pm 7.00$ & $41.00 \pm 5.40$ & 0.3027 \\
\hline $\operatorname{ALP}(\mathrm{U} / \mathrm{l})$ & $192.40(161.90)$ & $176.20(142.70)$ & 0.0322 \\
\hline \multicolumn{4}{|c|}{ Hepatocellular-cholestatic $(n, 5)$} \\
\hline AST $(\mathrm{U} / \mathrm{l})$ & $49.02(13.80)$ & $30.98(8.75)$ & 0.0625 \\
\hline $\operatorname{ALT}(\mathrm{U} / \mathrm{l})$ & $46.36(5.81)$ & $31.56(6.50)$ & 0.0625 \\
\hline GGT (U/l) & $213.30(42.84)$ & $161.70(49.99)$ & 0.0625 \\
\hline Total bilirubin $(\mu \mathrm{mol} / \mathrm{l})$ & $11.04(3.80)$ & $11.02(0.56)$ & 0.8125 \\
\hline Direct bilirubin $(\mu \mathrm{mol} / \mathrm{l})$ & $6.56(2.29)$ & $4.82(0.94)$ & 0.8125 \\
\hline Total proteins ${ }^{\dagger}(\mathrm{g} / \mathrm{dl})$ & $65.68 \pm 5.35$ & $74.00 \pm 2.92$ & 0.3125 \\
\hline Albumin $^{\dagger}(\mathrm{g} / \mathrm{dl})$ & $43.24 \pm 2.37$ & $43.40 \pm 1.29$ & $>0.9999$ \\
\hline $\operatorname{ALP}(\mathrm{U} / \mathrm{l})$ & $14.08(1.40)$ & $13.22(1.30)$ & $>0.9999$ \\
\hline
\end{tabular}

Data are presented as median (interquartile range (IQR)) (Wilcoxon matched-pairs signed-rank test); " $\dagger$ " indicates that data were parametric and were compared using paired $t$-test. $p \leq 0.05$ was considered significant when compared to baseline. AST: aspartate aminotransferase; ALT: alanine aminotransferase; GGT: gamma-glutamyltransferase; ALP: alkaline phosphatase.

anti-inflammatory properties [37-39]. These plants may act individually or in combination on the human liver to reduce hepatitis. Citrus aurantifolia can induce hepatoprotective enzymes, block genetic material damage in humans, and reverse cholestatic liver fibrosis caused by bile duct ligation $[40,41]$. These may also be part of the reasons why Heptonica improved the liver panel of participants which were deranged.

3.4.3. Effect of Heptonica on Different Aetiologies of Hepatic Impairment. Cholestatic injury is defined as a disproportionate elevation of ALP level as compared with AST and
ALT levels. Heptonica significantly improved AST, ALT, GGT, and total and direct bilirubin (Table 6) in participants with cholestatic liver disease. Heptonica may be responsible for the anti-inflammatory effect on the liver by reducing inflammatory enzymes AST and ALT. B pilosa and C. aurantifolia which are stated components of Heptonica have been established to possess anti-inflammatory activity on the liver by reversing hepatic fibrosis and blocking genetic damage to hepatocytes [42-44].

Accumulation of serum bilirubin levels above $3 \mathrm{mg} / \mathrm{dl}$ leads to jaundice (Figure 2). The excretory functions of the liver were enhanced significantly by the reduction of the bilirubin (total and direct). A previous animal study proved 


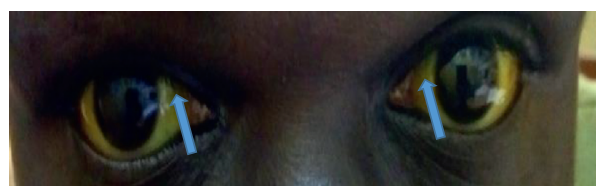

(a)

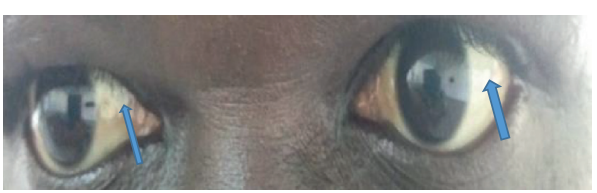

(b)

Figure 2: Participant with jaundiced eyes (a) and after 2 weeks of treatment (b).

that Citrus aurantifolia which is a component of Heptonica can reverse cholestatic liver fibrosis caused by the ligation of the bile duct [41]. Heptonica by reducing direct and total bilirubin may possess choleretic activity by causing more bile secretion or improving bile flow through the hepatic ducts. B. pilosa demonstrated protection of the liver against cholestatic liver disease in animal studies [45]. Demonstration of the clearance of jaundice from the eyes has been shown in Figure 2.

It was observed that participants with cholestatic liver disease experienced better improvement compared to those with a cholestatic-hepatocellular disease (Table 6). It is possible Heptonica may have improved the hepatocytes function, increased bile formation, and improved bile flow through the hepatic ducts. $B$. pilosa has been reported to normalize bilirubin concentration in blood [30].

Also, there was a significant improvement in the liver panel of participants with viral hepatitis with respect to AST, ALT, GGT, and total and direct bilirubin comparing the end of 28 days with the baseline (Table 7). It is a possibility that Heptonica significantly improved participants' deranged liver panel by viral hepatitis due to Heptonica's antiviral properties. Heptonica may have achieved the observed improved liver condition as an adaptogen stimulating and promoting hepatocytes regeneration and improving hepatocyte integrity [46].

Moreover, there were no significant differences between the baseline and the end of the 28-day study period in participants with deranged liver state of unknown origin. Details of the results are presented in Table 7. There was no indication that Heptonica could manage the actual cause of the derangement of these participants. Furthermore, there were no significant differences between the results of the baseline and the 28-day period in participants with alcoholic liver disease (Table 7). It is possible that Heptonica does not have much influence on the liver biochemistry of alcoholinduced liver diseases.

3.4.4. Effect of Heptonica on Quality of Life of the Participants. On day 0 , the mean score of $80 \pm 0.4$ Karnofsky scale of the participants improved significantly by day 28 to $91.40 \pm 1.21$ ( $p$ value $<0.0001)$. The improvement of quality of life may be from other activities of the product that were not investigated in this study. Some of the $94 \%$ of participants that had improved quality of life stated that they had better stamina, improved appetite, quality sleep, and general health benefits after taking Heptonica. Three clients (6\%) who were not responding to treatment on day 28 were referred to the allopathic section of the Upper West Regional Hospital for
TABLe 7: Heptonica on different aetiologies of liver impairment.

\begin{tabular}{|c|c|c|c|}
\hline & Day 0 & Day 28 & $p$ value \\
\hline \multicolumn{4}{|l|}{ Viral hepatitis $(n, 33)$} \\
\hline $\operatorname{AST}(\mathrm{U} / \mathrm{l})$ & $38.9(42.40)$ & $29.3(13.8)$ & 0.0001 \\
\hline $\operatorname{ALT}(\mathrm{U} / \mathrm{l})$ & $47.0(44.75)$ & $33.8(31.5)$ & 0.0014 \\
\hline GGT (U/l) & $55.0(121.50)$ & $39.2(101.45)$ & 0.0238 \\
\hline Total bilirubin $(\mu \mathrm{mol} / \mathrm{l})$ & $27.9(39.45)$ & $18.9(21.6)$ & 0.0353 \\
\hline Direct bilirubin $(\mu \mathrm{mol} / \mathrm{l})$ & $8.0(15.65)$ & $3.7 \pm(3.0)$ & 0.0005 \\
\hline Total proteins $^{\dagger}(\mathrm{g} / \mathrm{dl})$ & $70.8 \pm 13.25$ & $74 \pm 11.0$ & 0.2878 \\
\hline Albumin $^{\dagger}(\mathrm{g} / \mathrm{dl})$ & $42.96 \pm 8.20$ & $42 \pm 5.5$ & 0.3348 \\
\hline $\operatorname{ALP}(\mathrm{U} / \mathrm{l})$ & $204.4(167$. & 176.2( & 0.0163 \\
\hline \multicolumn{4}{|c|}{ Alcohol-induced liver disease $(n, 4)$} \\
\hline AST $(\mathrm{U} / \mathrm{l})$ & $87.9(20.7)$ & $49.0(16.2)$ & 0.3750 \\
\hline ALT & 87.1 & & 250 \\
\hline GGT $(\mathrm{U} / \mathrm{l})$ & $250.6(1$ & 107.5 & 0.1250 \\
\hline Total bilirubin $(\mu \mathrm{mol} / \mathrm{l})$ & $18.4(11.3)$ & $10.7(2.1)$ & 0.6250 \\
\hline Direct b & $6.5(3.3)$ & $5.7(0.9)$ & $>0.9999$ \\
\hline Total proteins ${ }^{\dagger}(\mathrm{g} / \mathrm{dl})$ & $71.5 \pm 5.9$ & $70.5 \pm 1.8$ & 0.8750 \\
\hline $\mathrm{l}^{\dagger}(\mathrm{g} / \mathrm{dl})$ & $37.25 \pm$ & $39.00 \pm$ & 0.6250 \\
\hline $\operatorname{ALP}(\mathrm{U} / \mathrm{l})$ & $145.2(40.2)$ & $78.00(26.1)$ & 0.1250 \\
\hline \multicolumn{4}{|l|}{ Unknown $(n, 11)$} \\
\hline $\mathrm{AST}(\mathrm{U} / \mathrm{l})$ & $25.5(27.0)$ & & 0.1472 \\
\hline $\operatorname{ALT}(\mathrm{U} / \mathrm{l})$ & $22.6(29.4)$ & $19.7(5.0)$ & 0.0674 \\
\hline GGT (U/1) & $24(114.3)$ & $23.4(24.0)$ & 0.1016 \\
\hline Total bilirubin $(\mu \mathrm{mol} / \mathrm{l})$ & $21.9(19.7)$ & $11.9(9.8)$ & 0.1426 \\
\hline Direct bilirubin $(\mu \mathrm{mol} / \mathrm{l})$ & $7.8(7.1)$ & $3.7(3.2)$ & 0.0693 \\
\hline Total proteins $^{\dagger}(\mathrm{g} / \mathrm{dl})$ & $66 \pm 18.4$ & $75 \pm 9.0$ & 0.1406 \\
\hline Albumin $^{\dagger}(\mathrm{g} / \mathrm{dl})$ & $44.8 \pm 7.0$ & $43 \pm 5.0$ & 0.5155 \\
\hline $\operatorname{ALP}(\mathrm{U} / \mathrm{l})$ & $128.6(121.3)$ & $135(186.9)$ & 0.8135 \\
\hline
\end{tabular}

Data are presented as median (interquartile range (IQR)) (Wilcoxon matched-pairs signed-rank test); " $\dagger$ " indicates that data were parametric and were compared using paired $t$-test. $p \leq 0.05$ was considered significant when compared to baseline. AST: aspartate aminotransferase; ALT: alanine aminotransferase; GGT: gamma-glutamyltransferase; ALP: alkaline phosphatase.

further management. The first was a case of hepatocellular carcinoma and the other two were on account of nonresolving ascites secondary to viral hepatitis. The treatment outcomes of participants demonstrated that Heptonica improved clients' quality of life.

\section{Conclusion}

Clinical evaluation of Heptonica on urinalysis, renal function, and haematological parameters within the 28-day period of administration showed evidence of safety and effectiveness in use in the management of some liver diseases in humans. On effectiveness, Heptonica improved significantly AST, ALT, GGT, and bilirubin (total and direct) levels of the 50 participants which were all deranged on day 0 
before the product administration. AST, ALT, GGT, total bilirubin, direct bilirubin, and alkaline phosphatase all had significant improvement compared to the baseline more especially in viral hepatitis and cholestatic liver diseases. The study has demonstrated that Heptonica has an effective hepatorestorative action with no observable toxicity and can be used with confidence as indicated as a liver tonic.

\section{Data Availability}

Raw data will be made available upon request to the corresponding author.

\section{Conflicts of Interest}

The authors declare that they have no conflicts of interest.

\section{Acknowledgments}

The authors would like to extend their sincere gratitude to the Centre for Plant Medicine Research, Upper West Regional Hospital, and Pharmacognosy Department of KNUST for all the support.

\section{References}

[1] P. Marcellin and B. K. Kutala, "Liver diseases: a major, neglected global public health problem requiring urgent actions and large-scale screening," Liver International, vol. 38, no. 1, pp. 2-6, 2018.

[2] WHO, WHO Global Mortality Report, WHO, Geneva, Switzerland, 2016.

[3] WHO, Global Hepatitis Report, https:/www.who.int/hepatitis/ publications/global-hepatitis-report2017/en/on 4/4/2019, WHO, Geneva, Switzerland, 2017, https://www.who.int/hepatitis/ publications/global-hepatitis-report2017/en/on 4/4/2019.

[4] S. K. Asrani, J. J. Larson, B. Yawn, T. M. Therneau, W. R. Kim, and W. R. Kim, "Underestimation of liver-related mortality in the United States," Gastroenterology, vol. 145, no. 2, pp. 375-382, 2013.

[5] "World health rankings (WHR)," 2017, https://www. worldlifeexpectancy.com/ghana-liver-disease on 5/4/2019.

[6] D. Schuppan and N. H. Afdhal, "Liver cirrhosis," The Lancet, vol. 371, no. 9615, pp. 838-851, 2008.

[7] J. A. Marrero, L. M. Kulik, C. B. Sirlin et al., "Diagnosis, staging, and management of hepatocellular carcinoma: 2018 practice guidance by the American Association for the Study of Liver Diseases," Hepatology, vol. 68, no. 2, pp. 723-750, 2018.

[8] E. Madrigal-santillán, E. Madrigal-bujaidar, I. Álvarezgonzález et al., "Review of natural products with hepatoprotective effects," Evidence-Based Complementary and Alternative Medicine, vol. 20, no. 40, pp. 14787-14804, 2014.

[9] A. Sofowora, E. Ogunbodede, and A. Onayade, "The role and place of medicinal plants in the strategies for disease," African Journal of Traditional Complementary Medicine and Alternative Medicine, vol. 10, no. 5, pp. 210-229, 2013.

[10] P. Uhl, G. Fricker, U. Haberkorn, and W. Mier, "Current status in the therapy of liver diseases," International Journal of Molecular Sciences, vol. 15, no. 5, pp. 7500-7512, 2014.

[11] S. Kumar, A. Gupta, M. Revadekar, S. More, A. Kulkarni, and S. Borkar, "Efficacy and safety of Hepano tablet in liver disorder patients with abnormal liver function test: a randomized active controlled prospective clinical study," Drug Development and Therapeutics, vol. 8, no. 1, pp. 6-12, 2017.

[12] R. K. Dhiman and Y. K. Chawla, "Herbal medicines for liver diseases," Digestive Diseases and Sciences, vol. 50, no. 10, pp. 1807-1812, 2005.

[13] F. Stickel, E. Patsenker, and D. Schuppan, "Herbal hepatotoxicity," Journal of Hepatology, vol. 43, no. 5, pp. 901-910, 2005.

[14] B. Lawal, O. K. Shittu, F. I. Oibiokpa, E. B. Berinyuy, and H. Mohammed, "African natural products with potential antioxidants and hepatoprotectives properties: a review," Clinical Phytoscience, vol. 2, no. 1, p. 23, 2016.

[15] M. Elfil and A. Negida, "Sampling methods in clinical research; an educational review," Emergency, vol. 5, no. 1, p. e52, 2017.

[16] M. Casteels and B. Flamion, "Open-label trials and drug registration: a European regulator's view," Journal of Thrombosis and Haemostasis, vol. 6, no. 2, pp. 232-234, 2008.

[17] S. Ballou, T. J. Kaptchuk, W. Hirsch et al., "Open-label versus double-blind placebo treatment in irritable bowel syndrome: study protocol for a randomized controlled trial," Trials, vol. 18, no. 1, p. 234, 2017.

[18] A. Mishra, P. Shrestha, N. Bista et al., "Pattern of liver diseases," Journal of Nepal Health Research Council, vol. 7, no. 1, pp. 14-18, 2009.

[19] G. Mutinta, "Multiple sexual partnerships and their underlying risk influences at the University of KwaZulu-Natal," Journal of Human Ecology, vol. 46, no. 2, pp. 147-155, 2014.

[20] O. A. Abulude, I. 1. Ahmed, and F. U. Sadisu, "Assessment of Hepatitis B viral infection as a predictor of hepatic enzymes and compounds alteration among antenatal patients," Medical Sciences, vol. 5, no. 4, p. 24, 2017.

[21] S. Uchino, R. Bellomo, and D. Goldsmith, "The meaning of the blood urea nitrogen/creatinine ratio in acute kidney injury," Clinical Kidney Journal, vol. 5, no. 2, pp. 187-191, 2012.

[22] H. El-Kabany and S. I. Ibrahim, "Effect of Bidens pilosa extract on renal functions and some tumor markers of Ehrlich ascites carcinoma bearing mice exposed to $\gamma$-radiation'," Journal of Radiation Research and Applied Sciences, vol. 6, no. 1, pp. 155-174, 2013.

[23] J. S. Aprioku and A. W. Obianime, "Evaluation of the effects of citrus aurantifolia (lime) juice in lead-induced hematological and testicular toxicity in rats," Pharmacologia, vol. 5, no. 1, pp. 36-41, 2014.

[24] N. Dosoky and W. Setzer, "Biological activities and safety of Citrus spp. essential oils," International Journal of Molecular Sciences, vol. 19, no. 7, p. 1966, 2018.

[25] T. Hemalatha, D. Ahino Mary, and A. Saravana Ganthi, "Acute and sub-acute toxicity study of Trema orientalis (L.) Bl. methanol extract in rats," Journal of Drug Delivery and Therapeutics, vol. 9, no. 1-s, pp. 307-311, 2019.

[26] M. Sja'bani, M. Ismadi, S. D. Ismiati, R. P. Sidabutar, and D. Rahardjo, "The therapeutic effect of Citrus aurantifolia swingle in idiopathic hypocitraturic calcium nephrolithiasis," Berkala Ilmu Kedokteran, vol. 39, no. 4, pp. 199-208, 2007.

[27] K. Bairwa, R. Kumar, R. J. Sharma, and R. K. Roy, "An updated review on Bidens pilosa L," Der Pharma Chemica, vol. 2, no. 3, pp. 325-337, 2010.

[28] N. Narang and W. Jiraungkoorkul, "Anticancer activity of key lime, Citrus aurantifolia," Plant Review, vol. 10, no. 20, p. 118, 2016.

[29] J. Rout, A. L. Sajem, M. Nath, and M. Sengupta, “Antibacterial efficacy of bark extracts of an ethnomedicinal plant Trema 
orientalis Blume," Current Trends in Biotechnology and Pharmacy, vol. 6, no. 4, pp. 464-471, 2012.

[30] S. E. Potawale, V. M. Shinde, U. N. Harle et al., "Bidens pilosa L.: a comprehensive review," PharmacologyOnLine, vol. 2, pp. 185-196, 2008.

[31] P. Valaskova, L. Muchova, and P. M. Rudd, "Metabolism of bilirubin and its biological properties," Clinical Biochemistry and Metabolism, vol. 24, no. 4, pp. 198-202, 2016.

[32] R. Teferi, C. A. Hanson, and D. J. Inwards, "How to interpret and pursue an abnormal complete blood cell count in adults, concise review for Clinicians," Mayo Clinic Proceedings, vol. 80, no. 7, pp. 923-936, 2005.

[33] M. J. Moshi, D. F. Otieno, and A. Weisheit, "Ethnomedicine of the kagera region, north western Tanzania. Part 3: plants used in traditional medicine in kikuku village, muleba district," Journal of Ethnobiology and Ethnomedicine, vol. 8, no. 1, p. 14, 2012.

[34] J. E. Olajide, S. Momoh, O. J. Achimugu, and E. R. Jegede, "Effects of Trema orientalis leaves extract on hematological parameters of cadmium induced toxicity in wistar rats," IOSR Journal of Biotechnology and Biochemistry (IOSR-JBB), vol. 6, no. 1, pp. 01-07, 2020.

[35] A. K. Widowati, N. H. Hikmayani, and E. P. Pamungkasari, "Antipyretic effect of key lime (Citrus aurantiifolium) leaf extract on white rats," Biofarmasi Journal of Natural Product Biochemistry, vol. 10, no. 2, pp. 35-39, 2012.

[36] T. Luedde, N. Kaplowittz, and R. F. Schwabe, "Cell death and cell death response in liver disease: mechanisms and clinical relevance," Gastroenterology, vol. 147, no. 4, pp. 765-783, 2015.

[37] S. N. Uddin, "Antioxidant and antibacterial activities of Trema orientalis Linn: an indigenous medicinal plant of Indian Subcontinent," Oriental Pharmacy and Experimental Medicine, vol. 4, no. 3, pp. 395-399, 2008.

[38] F. N. Njayou, P. F. Mounndipa, A. N. Tchana, B. T. Ngadjui, and F. M. Tchouanguep, "Inhibition of microsomal lipid peroxidation and protein oxidation by extracts from plants used in Bamun folk medicine (Cameroon) against Hepatitis," Africa Journal of Traditional Medicine, vol. 5, no. 3, pp. 278-289, 2008.

[39] D. Gonçalves, C. Lima, P. Ferreira et al., "Orange juice as dietary source of antioxidants for patients with hepatitis C under antiviral therapy," Food \& Nutrition Research, vol. 61, no. 1, Article ID 1296675, 2017.

[40] D. E. Okwu and I. N. Eminike, "Evaluation of the phytonutrients and vitamin C content of citrus fruits," International Journal of Molecular Medicine and Advance Sciences, vol. 2, no. 1, pp. 1-6, 2006.

[41] S.-W. Lim, D.-R. Lee, B.-K. Choi et al., "Protective effects of a polymethoxy flavonoids-rich Citrus aurantium peel extract on liver fibrosis induced by bile duct ligation in mice," Asian Pacific Journal of Tropical Medicine, vol. 9, no. 12, pp. 11581164, 2016.

[42] O. A. T. Ashafa and A. J. Afolayan, "Screening the root extracts from Biden pilosa L. var. radiata (Asteraceae) for antimicrobial potentials," Journal of Medicinal Plants Research, vol. 3, no. 8, pp. 568-572, 2009.

[43] M. R. Kviecinski, K. B. Felipe, J. F. Gomes Correia et al., "Brazilian Bidens pilosa Linné yields fraction containing quercetin-derived flavonoid with free radical scavenger activity and hepatoprotective effects," Libyan Journal of Medicine, vol. 6, no. 1, p. 5651, 2011.
[44] N. E. Rawson, C.-T. Ho, and S. Li, "Efficacious anti-cancer property of flavonoids from citrus peels," Food Science and Human Wellness, vol. 3, no. 3-4, pp. 104-109, 2014.

[45] M. I. Suzigan, A. P. R. Battochio, K. L. R. Coelho, and C. A. R. Coelho, "An acqueous extract of Bidens pilosa L. protects liver from cholestatic disease: experimental study in young rats," Acta Cirurgica Brasileira, vol. 24, no. 5, pp. 347-352, 2009.

[46] P. K. Mukherjee, N. K. Nema, S. Bhadra, D. Mukherjee, F. C. Braga, and M. G. Matsabisa, "Immunomodulatory leads from medicinal plants," Indian Journal of Traditional Knowledge, vol. 13, no. 2, pp. 235-256, 2014. 